\title{
OCORRÊNCIA DE COCCÍDEOS PSEUDOPARASITOS EM CARNÍVOROS
}

\author{
Occurrence of pseudoparasite coccidians in carnivores
}

\author{
GRESSLER, L.T. ${ }^{1}$; Da SILVA, A.S. ${ }^{1}$; OLIVEIRA, C.B. ${ }^{1}$; SOARES, J.F. ${ }^{1}$; \\ MONTEIRO, S.G. ${ }^{1}$
}

\author{
1 Universidade Federal de Santa Maria
}

Endereço para correspondência: Silvia Gonzalez Monteiro: sgmonteiro@uol.com.br

\section{RESUMO}

O objetivo deste trabalho foi relatar a ocorrência de pseudoparasitos em três espécies de carnívoros (Felis catus, Lycalopex gymnocercus e Canis lupus familiaris) no sul do Brasil. Amostras de fezes colhidas em exame de rotina dos animais foram processadas através da técnica de centrífugo-flutuação com sulfato de zinco. Em microscópio óptico foram detectados oocistos esporulados e não esporulados de coccídios da família Adeleidae em gato doméstico e graxaim-do-campo. Nas fezes do canídeo foram encontrados oocistos de Eimeria sp. Ambos protozoários não são patogênicos para estas espécies hospedeiras, porém, podem ser facilmente confundidos com outros coccídeos virulentos quando não estão esporulados.

Palavras-chave: canídeos; coccídeos; felídeos; pseudoparasitismo

\begin{abstract}
The aim of this research study was to report the occurrence of pseudoparasites in three species of carnivores (Felis catus, Lycalopex gymnocercus and Canis lupus familiaris) in the southern region of Brazil. Fecal samples collected in the routine examination of the animals were analyzed by the centrifugal flotation technique with zinc sulfate. Sporulated and nonsporulated oocysts of coccidia of the family Adeleidae were observed in the feces of the domestic cat and pampas-fox. Oocysts of Eimeria sp. were present in the dog feces. Although not pathogenic for these host species, these oocysts can be easily confounded with other virulent coccidian when present in their nonsporulated form.
\end{abstract}

Key words: canids; coccidian; felidae; pseudoparasitism 


\section{INTRODUÇÃO}

O Filo Protozoa apresenta uma ampla e heterogênea diversidade de microrganismos (Brooks, 1988). Os Apicomplexos (Sporozoa) de interesse são parasitos intracelulares obrigatórios que causam doença devido à destruição das células parasitadas. Destes, os membros mais importantes são os coccídeos, muitos dos quais se desenvolvem nas células epiteliais do trato digestivo causando uma forma de enterite denominada coccidiose (Bowman et al., 2006).

Os coccídeos são considerados um grande grupo, separados em outros dois subgrupos: Adeleidae e Eimeriidae, um mais primitivo e o outro mais avançado, respectivamente. Porém, estes apresentam ciclos biológicos similares (Cox, 1994). A família Eimeriidae é formada por vários gêneros, onde Cystoisospora spp. e Eimeria spp. apresentam maior interesse em medicina veterinária (Pessoa, 1998).

A maioria desses organismos são parasitos e/ou comensais de vertebrados, porém encontrados no trato digestivo do hospedeiro muitas vezes podem estar associado à ingestão de invertebrados parasitados, como os coccídos da Família Adeleidae (Brooks, 1988). Devido à alta resistência dos oocistos, um grande número de protozoários é capaz de passar através da parede do trato intestinal sem qualquer alteração em suas características morfológicas. Os Adeleidae são frequentemente observados em hospedeiros invertebrados e ocasionalmente no conteúdo intestinal de seus predadores. Tais situações foram responsáveis por errôneamente considerarem vertebrados como sendo seus hospedeiros definitivos (Duszynski et al., 2003).

Nos exames de fezes de mamíferos, os coccídeos, quando não esporulados não permitem a diferenciação de gêneros (Bowman et al., 2006). Este artigo chama a atenção para a prova de esporulação em placa, a fim de obter-se um diagnóstico correto, além de ter como objetivo relatar a ocorrência de pseudoparasitismo em três espécies de carnívoros por coccídios da família Adeleidae e Eimeridae.

\section{MATERIAL E MÉTODOS}

Em exames parasitológicos de rotina foram analisadas amostras de fezes de três carnívoros através da técnica de centrífugo-flutuação com sulfato de zinco. No ano de 2007, foram analisadas fezes de um graxaim do campo (Lycalopex gymnocercus), de vida livre, encontrado debilitado e com escoriações profundas pelo corpo. O mesmo foi atendido no consultório veterinário do zoológico do município de Cachoeira do Sul, RS. Nas fezes deste animal observou-se a presença de oocistos de coccídios.

Em 2008, oocistos de protozoários foram identificados em amostras de fezes de um gato doméstico (Felis catus), macho, com idade de nove meses, SRD. O mesmo era mantido em apartamento, no centro da cidade de Santa Maria - RS e não tinha acesso à rua.

No ano de 2009, oocistos de parasitos foram visualizados em fezes de um canídeo (Canis lupus familiaris) com 1,5 anos de idade, da raça Daschund. $O$ animal alimentava-se de ração e de acordo com a proprietária, caçava aves e invertebrados. Esse residia em uma casa com um grande quintal.

Em todos os casos, após a identificação dos coccídeos, as amostras de fezes foram alocadas em placas de petri e mantidas em temperatura e umidade controlada (25 ${ }^{\circ} \mathrm{C} ; 70 \%$ UR) para a esporulação dos oocistos. As amostras foram observadas em microscópio óptico em aumentos de 100, 200 e 400 vezes e as formas imaturas medidas, fotografadas e identificadas. 


\section{RESULTADOS E DISCUSSÃO}

No graxaim-do-campo foram encontrados 26 oocistos que possuíam limites medindo entre $31 \times 26$ por $29 \times 23 \mu \mathrm{m}$. Quando esporulados apresentavam cinco esporocistos com dimensões entre $11 \times 7$ por $10 \times 6 \mu \mathrm{m}$ (Figura 1B). Os oocistos apresentavam formas ovaladas e seus esporocistos formato oval. Nas fezes do gato doméstico foram visualizados 17 oocistos com dimensões de 37,9 x 35,4 por $36 \times 33,5 \mu \mathrm{m}$ (Figura 1A). Após a esporulação foram observados no interior dos oocistos a presença de quatro a cinco esporocistos medindo entre 17,7 x 15,1 por $15,9 \times 14,1 \mu \mathrm{m}$ (Figura 1C). Os oocistos e esporocistos apresentavam forma esférica. Ambos coccídeos encontrados nesses animais são compatíveis com membros da família Adeleidae, pois morfologicamente estes oocistos diferem dos da família Eimeriidae, principalmente, pelo número de esporocistos e esporozoítas (Duszynski et al., 2003). A membrana celular dos oocistos de Adeleidae é simples (Figura 1), ao contrario dos eirmerídeos (Davies et al., 1963; Brooks, 1988; Duszynski et al., 2003). Outro fator que pode auxiliar no diagnóstico é conhecer os hábitos alimentares do hospedeiro, pois se 0 animal ingere artrópode, e nas fezes são observados oocistos com mais de quatro esporocistos pode-se tratar de um pseudoparasitismo por protozoários da Família Adeleidae, na realidade estas formas imaturas são parasitos do invertebrado (Duszynski et al., 2003).

O cão apresentava fezes mucóides e diarréicas. No exame de fezes foi observado pela técnica de centrífugoflutuação um grande número de oocistos de coccídios, não esporulados, com medidas entre 20,3 x 18,0 por 18,0 x 16,9 $\mu \mathrm{m}$. Em um primeiro momento suspeitou-se de parasitismo por Cystoisospora sp., no entanto esta hipótese foi questionada quando foram encontrados oocistos esporulados contendo em seu interior quatro esporocistos medindo $7,9 \times 6,7$ por 6,7 x 4,5 $\mu \mathrm{m}$ (Figura 1D). Uma amostra de fezes foi submetida à esporulação no laboratório e outra foi encaminhada ao Laboratório de Coccídios e Coccidioses da Universidade Federal do Rio de Janeiro a fins de diagnóstico. Em ambas as situações os oocistos foram identificados como pertencentes ao gênero Eimeria. Esta classificação foi baseada na morfologia dos oocistos, que segundo a literatura (Davies et al., 1963), apresentam estrutura esférica a piriforme, translúcida, com parede dupla e contendo quatro esporocistos com dois esporozoítas no seu interior.

Duszynski (1969) encontrou em lagartos costarriquenhos, oocistos comtendo 16 esporocistos, e cada esporocisto apresentando quatro esporozoítos. Estes foram classificados como pertencentes ao gênero Pythonella. Mais tarde, McQuistion (1990) descreveu oocistos com 9 a 15 esporocistos nas fezes de uma ave (Nesomimus parvulus), estes foram identificados como sendo de Polysporella genovesae. Em Didelphis aurita (gambá-de-orelha-branca), um coccídio Adeleidie medindo em torno de $34,28 \pm 4,51$ por $31,63 \pm 4,62 \mu \mathrm{m}$ de diâmetro, contendo de 8 a 12 esporocistos foi reportado como um pseudoparasito (Teixeira et al., 2003). Estes autores sugerem aos parasitologistas cautela no diagnóstico, devido à possibilidade de falsos parasitismos decorrente da dieta destes animais ser rica em artrópodes, hospedeiros comuns de Adeleidae.

As formas de coccídeos encontradas nos carnívoros deste estudo são consideradas pseudoparasitos, já que a família Adeleidae parasita invertebrados e o gênero Eimeria não parasita carnívoros em geral (Ghosh et al., 2000; Lange et al., 2001; Teixeira et al., 2003; Bowman et al., 2006). Em cães e gatos a verdadeira infecção ocorre por espécies 

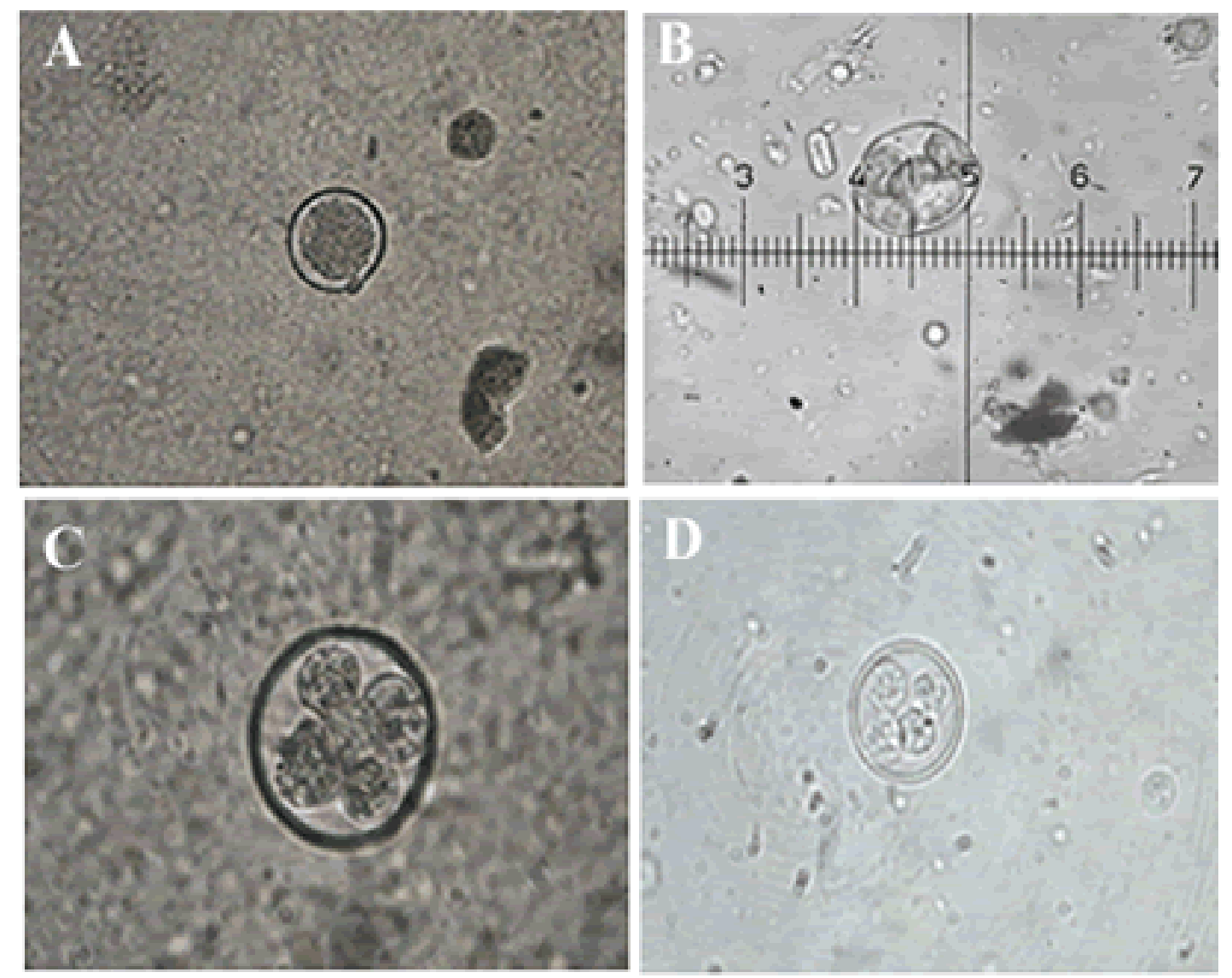

Figura 1: Fotomicrografia dos oocistos de pseudoparasitos encontrados em fezes de carnívoros por meio de exame parasitológico de centrífugo-flutuação. Oocisto não esporulado com dimensões de 37,9 x 35,4 por 36 × 33,5 $\mu \mathrm{m}$ (A) e oocisto esporulado, com esporocistos com dimensões de 17,7 x 15,1 por $15,9 \times 14,1 \mu \mathrm{m}(\mathrm{C})$ encontrados nas fezes de um gato. Oocisto esporulado encontrado ns fezes de um graxaim-do-campo, com medidas de $31 \times 26$ por $29 \times 23 \mu \mathrm{m}$ e esporocistos medindo $11 \times 7$ por $10 \times 6$ $\mu \mathrm{m}$ (B). No cão foram visualizados oocistos esporulado com dimensões de 20,3 x 18,0 por 18,0 x 16,9 $\mu \mathrm{m}$ e esporocistos dimensões de $7,9 \times 6,7$ por 6,7 x 4,5 $\mu \mathrm{m}$ (D). ${ }^{*}$ Imagens em aumento de 200 vezes.

do gênero Cystoisospora, causando diarréia principalmente em animais jovens (Bowman et al., 2006).

Pelo fato do gato apresentar alguns oocistos com quatro esporocistos, poderia se pensar no gênero Eimeria. Entretanto, este gênero não causa infecção em carnívoros (Rey, 2001). Já, os coccídios identificados nas fezes do graxaim-docampo apresentaram formas totalmente distintas dos eimerídeos (Figura 1B). No gato $e$ no graxaim-do-campo foram encontradas duas espécies de adeleidae, que possivelmente foram oriundas da dieta destes animais, baseada em artrópodes como gafanhotos, baratas, grilos e cascudos (insetos), caçados ou ingeridos acidentalmente, sendo já descrita a presença do gênero Adelina em tecidos e fluidos corporais de insetos como grilos (Rioux et al., 1984; Ghosh et al., 2000; Lange et al., 2001).

Conforme Rey (2001) e Bowman et al. (2006), o gênero Eimeria não causa sinais clínicos em cães. No entanto, não saberíamos explicar o motivo do cão apresentar fezes mucóides e diarréicas. Neste caso faltou pesquisar o motivo da diarréia, isso poderia esclarecer se a Eimeria sp. estava sendo patogênica para o cão ou o sinal clínico foi oriundo de outras causas. Segundo o proprietário, o cão apresentava hábitos de caçar invertebrados e aves que poderiam ser os prováveis hospedeiros. Devido à grande quantidade de oocistos encontrada no material analisado, não se 
descarta a possibilidade deste cão ter 0 costume de ingerir fezes de aves.

\section{CONCLUSÕES}

O presente relato tem como finalidade chamar a atenção dos clínicos veterinários para a importância do diagnóstico diferencial através da esporulação dos oocistos de coccídios para evitar diagnósticos falso-positivos de coccídiose e conseqüentes tratamentos desnecessários. Com base nos resultados obtidos no presente estudo, podemos concluir que coccídios Adeleidae e Eimeria sp. são pseudoparasitos de carnívoros.

\section{REFERÊNCIAS}

BOWMAN, D.D.; LYNN, R.C.; EBERHARD, M.L.; ALCARAZ, A. Parasitologia Veterinária de Georgis. São Paulo, Manole, 2006. 60p.

BROOKS, W. M. Entomogenous protozoa. In: IGNOFFO, C.M. CRC Handbook of Natural Pesticides. Boca Raton: CRC Press, 1988, p.1-7.

COX, F.E.G. The evolutionary expansion of the Sporozoa. International Journal of Parasitology, v.24, p.1301-1316, 1994.

DAVIES, S. F. M.; JOYNER, L. P.; KENDALL, S. B. Coccidiosis. Londres: Oliver and Boyd LTD, 1963, p.12-13.

DUSZYNSKI, D.W. Pythonella scelopori sp. n. (Protozoa: Eimeriidae) from a Costa Rican Lizard. Journal of Parasitology, v.55, p.684-685, 1969.
DUSZYNSKI, D.W.; COUCH, L.; UPTON, S.J. Genera (Eimeriidae) of dubious vality. 2003. Disponível em: <http://www.ksu.edu/parasitology/worldcoccidia/IN VALID?> Acesso em 15 maio de 2008.

GHOSH, C.; CHOUDHURY, A.; MISRA, K.K. Life histories of three new coccidian parasites from three coleopteran stored-grain pests of India. Acta Protozoologica, v.39, p.233-240, 2000.

LANGE, C.E.; WITTENSTEIN, E. An Adelina sp. (Apicomplexa: Coccidia) Found in Anurogullus muticus (DeGeer) (Orthoptera: Gryllidae). Journal of Invertebrate Pathology, v.77, p.83-84, 2001.

McQUISTION, T.E. Pollysporella genonesae n. gen., n. sp. (Apicomplexa: Eimeriidae) from the fecal contents of the Galopagos Mockingbird, Nesomimus parvulus (Passeriformes: Mimiidae). Transactions of the American Microbiology Society, v.109, p.412-416, 1990.

PESSOA, S.B.; MARTINS, A.V.; Parasitologia Médica. 11 ed. Rio de Janeiro: Ed. Guanabara, 1988. 246p.

REY, L. Parasitologia. 3 ed. Rio de Janeiro: Ed. Guanabara Koogan, 2001. 856p.

RIOUX, J.A.; BELMONTE, A.; MAAZOUN, R. Prèsence en France Continentale D'Adelina rioux Levine, 1977 (Coccidia-Adeleidae). Annales di Parasitologie Humane et Compare, v.59, p.635, 1984.

TEIXEIRA, M.; ALBUQUERQUE, G.R.; LOPES, C.W.G.; FLORENTINO, M.V.N. An adeleid coccidia, pseudoparasite of Didelphis aurita (Marsupialia: Didelphoidea). Revista Brasileira de Parasitologia Veterinária, v.12, n.1, p.43-45, 2003. 